\title{
A música na conceção e na prática teatral do século XIX em Portugal
}

\section{lsabel Novais Gonçalves}

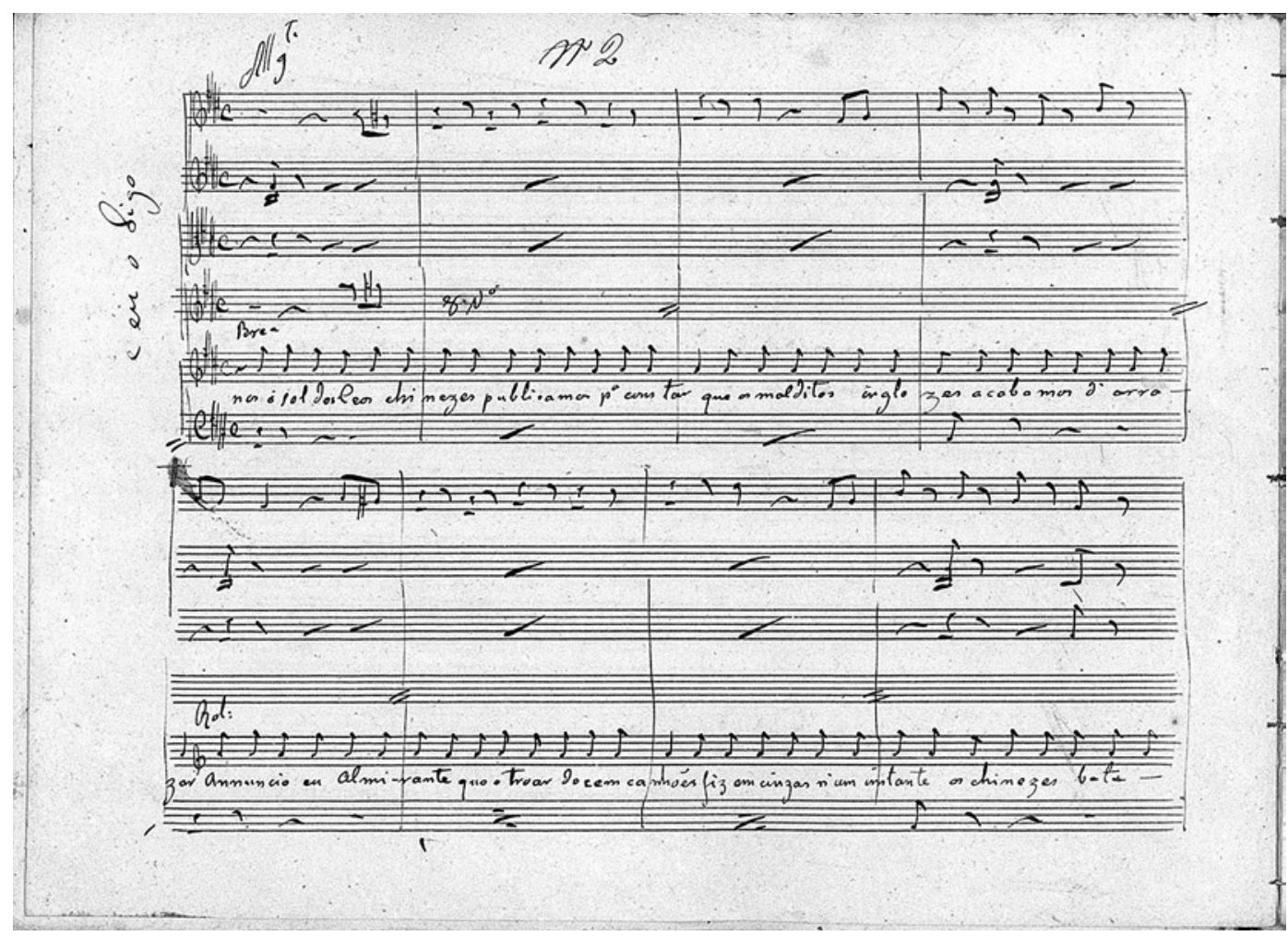

O século XIX foi território, por excelência, de uma conjuntura teatral rica e complexa. A natureza heterogénea do repertório e a variedade de géneros teatrais em circulação nos palcos portugueses refletiam-se na arte de encenar e interpretar. Dramas, Comédias, Mágicas, Farsas, Paródias e Revistas, com maior ou menor diferença, desenvolviam os seus próprios processos dramatúrgicos e cénicos e alimentavam gostos diversificados no público e mesmo públicos distintos. Mas a música atravessava todos os géneros sem exceção e desempenhava um contributo fundamental na transposição dos textos dramáticos para o palco, e para o seu posterior sucesso - ou falhanço.

"O publico quer musica, quer chácaras", escrevia Luís
Augusto Palmeirim no jornal A Restauração, na análise que fazia ao panorama teatral lisboeta de 1845 (10.01.1845). Às xácaras o cronista podia ter acrescentado duetos, marchas, romances ou qualquer outro tipo de números musicais que, em parceria com os restantes recursos - corpo, movimento, palavra, cenário e caracterização -, faziam de cada retorno ao enredo dramático um espetáculo único e exclusivo, mas capaz de deixar no seu público um pacote vivo de memórias. Qualquer empresário teatral sabia disso, não poupando esforços para contratar um compositor e manter uma orquestra em permanência, pronta a encher o palco e a plateia de xácaras e coplas sonantes que agarravam o ouvido do espectador mais distraído. lsabel Novais Gonçalve tem o curso geral de piano pelo Conservatório do Porto é licenciada em Ensino da Música pela ESE do Instituto Politécnico do Porto e em Ciências Musicais pela FCSH da Universidade Nova de Lisboa. Fez o doutoramento em Ciências Musicais com a tese $A$ música teatra na Lisboa de Oitocentos: uma abordagem através $d$ obra de Joaquim Casimiro Júnior (18081862). É membro do Centro de Estudos de Sociologia e Estética Musical, onde integra o projeto de investigação "Teatro para rir: A comédia musical em teatros de lingua portuguesa (1849-1900)." É musicóloga na CML, no Serviço de Fonoteca da Rede de Bibliotecas de Lisboa, onde presta serviço de referência, faz a gestão da coleção e desenvolve atividades educativas e culturais na área da música. 
Ainda que sob uma matriz relativamente genérica, o grau e a forma de participação musical no teatro declamado dependia das características internas das peças e da intervenção dos dramaturgos, compositores e encenadores. Mas era fundamentalmente no território da escrita, no sossego do gabinete, onde o autor dramático congeminava a grande intriga ou uma simples historieta, que se definiam todos os momentos de intervenção musical de uma peça. A razão para esse cuidado acrescido, no meio do investimento literário, prende-se com um facto tão simples quanto crucial - a música não constituía mero recurso decorativo do pôr-em-cena mas parte integrante da lógica construtiva do texto teatral oitocentista.

\section{Categorias musicais em jogo na cena}

0 papel da música é particularmente evidente nos dramas, sobretudo nos de moldura histórica, onde a recorrência de personagens-músicos (trovadores, jograis, menestréis ou bobos) ou de cenas de festas, bailes, cortejos ou cerimónias, solicitavam o elemento musical como parte integrante da ação, vinculando-o a uma categoria funcional que podemos designar de "música como representação de música" - e que está naturalmente presente também nos restantes géneros dramáticos, como se pode ver nos seguintes exemplos de peças levadas à cena na Lisboa de Oitocentos:

\begin{tabular}{|c|c|c|}
\hline Peça & Didascálias / deixas & Categoria \\
\hline $\begin{array}{l}\text { Dulce, } \\
\text { drama, original de Bento Leão da Cunha } \\
\text { Carvalhais. } \\
\text { Ato / cena } \\
\text { 1. } / \text { /II }\end{array}$ & $\begin{array}{l}\text { D. BIBAS, cantando e acompanhando-se no bandolim } \\
\text { Dulce é pura, há de escapar-te, } \\
\text { Demonio de Dom Garcia! } \\
\text { [...] } \\
\text { GARCIA, levantando-se, e com ira. } \\
\text { Maldicto jogral! Sáe d'aqui já. A tua bôcca é damnada e mais que maldicta! } \\
\text { [...] }\end{array}$ & $\begin{array}{l}\text { Música como } \\
\text { representação de } \\
\text { música: } \\
\text { Canção por } \\
\text { personagem músico - } \\
\text { jogral }\end{array}$ \\
\hline $\begin{array}{l}\text { A lotaria do diabo, } \\
\text { mágica, imitação de Joaquim Augusto de Oliveira } \\
\text { e Francisco Palha; música de Joaquim Casimiro } \\
\text { Júnior (T. Variedades, 1858) }\end{array}$ & $\begin{array}{l}\text { ZAIRA. E quando vier a noite, Amina te cantará ao som do alaude os cantos } \\
\text { melancholicos que sua mãe compunha quando te acalentava! } \\
\text { AMINA. Tantas vezes Ih'os ouviste!...lembras-te? } \\
\text { TERCETINO: } \\
\text { [...] } \\
\text { AZAIM. Esta doce recordação do passado, este ecco da } \\
\text { felicidade antiga - consolou-me, fez-me bem. }\end{array}$ & $\begin{array}{l}\text { Música como } \\
\text { representação de } \\
\text { música: } \\
\text { trio cantado por } \\
\text { personagens em } \\
\text { contexto intimo }\end{array}$ \\
\hline $\begin{array}{l}\text { As profecias do Bandarra, } \\
\text { comédia, original de Almeida Garrett } \\
\text { (Teatro D. Maria II, 1858) }\end{array}$ & $\begin{array}{l}\text { Catarina, Pantaleão [...], Lázaro e os praticantes com tochas, [...] em forma } \\
\text { de procissão. Inclinam-se diante do retrato de D. Sebastião e formam alas } \\
\text { [...]. } 0 \text { coro vem cantando. }\end{array}$ & $\begin{array}{l}\text { Música como } \\
\text { representação de } \\
\text { música: coro } \\
\text { integrado em } \\
\text { cerimónia }\end{array}$ \\
\hline
\end{tabular}


Em cada um destes excertos, a inserção musical surge no contexto da cena, enquadra-se na lógica da verosimilhança e participa ativamente na construção de um teatro ilusório. 0 canto e a dança são convocados para moldar personagens ou reproduzir no palco vivências de um quotidiano íntimo, social ou ritualista, ainda que dramaticamente formatado.
Aparentemente nos antipodas da "música como representação de música", há inúmeras inserções musicais vocais, persistentes sobretudo nas comédias e géneros afins, reconduziveis a uma categoria funcional de "música como fim em si". Coplas (assim designadas pela estrutura textual e musical genericamente estrófica), bem como duetos, trios, quartetos e coros interrompiam assumidamente a ação para proporcionar momentos de pura exibição musical à plateia:

\begin{tabular}{llc}
\hline Peça & Didascálias / deixas & Categoria \\
\hline A lotaria do Diabo & PATERNo (rindo). Eh! Eh! Eh! Viveis cincoenta annos?! Eu vos provo o & Música como fim em \\
& contrario. & si: copla \\
Ato / cena & COPLA & \\
$3 .{ }^{\prime} /$ III & Cincoenta anos!! Já - já tirar d'elles \\
& Os vinte annos que ao somno entregaes! \\
& {$[\ldots]$}
\end{tabular}

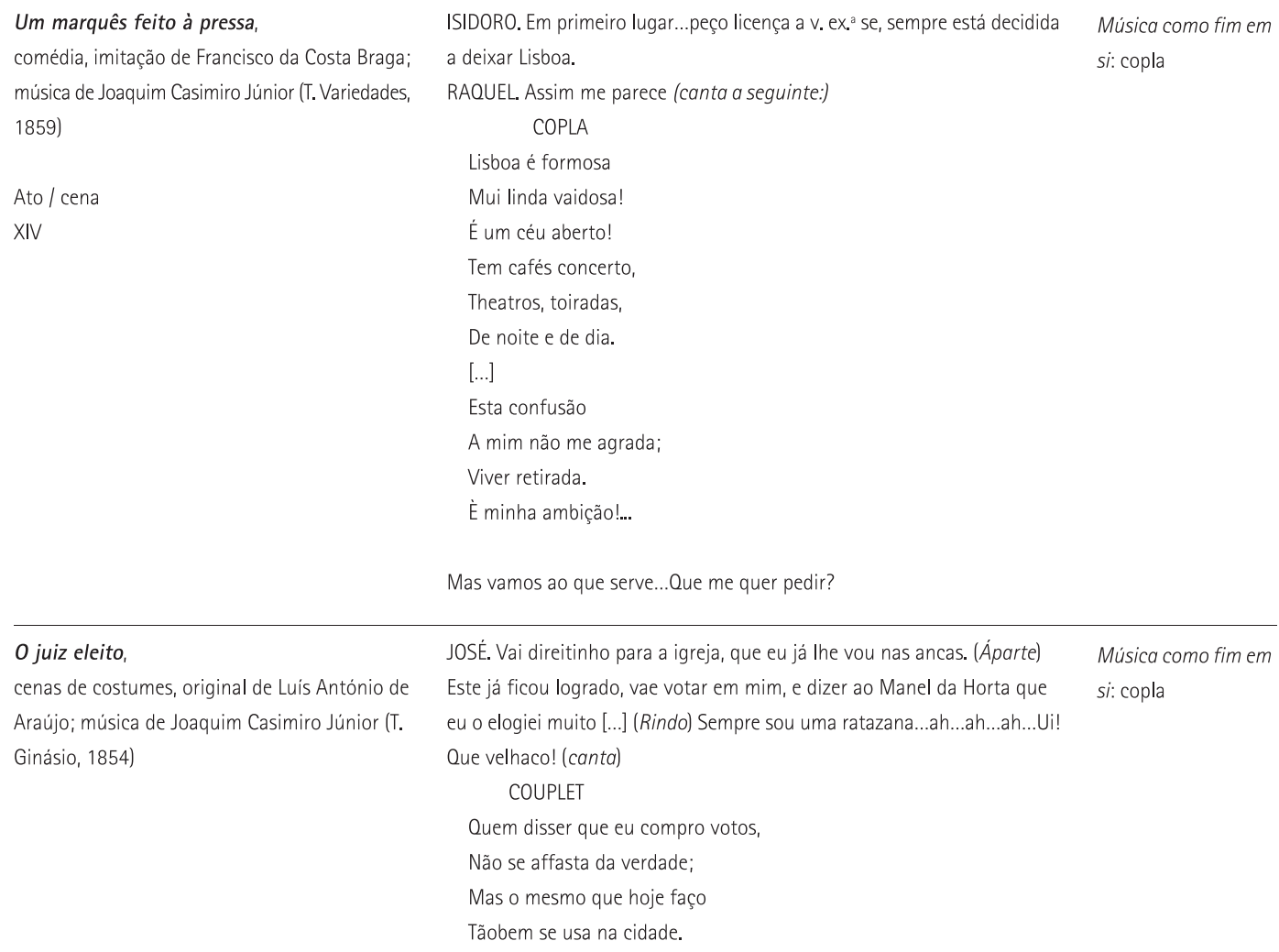


Nenhuma das coplas expostas tem consequência no desenvolvimento do enredo ou uma justificação dramática a enquadrá-las. Se no processo de encenação o canto fosse convertido em declamação, ou mesmo suprimido, tal não alteraria o rumo da intriga. Mas precisamente porque a sua função era a de surpreender, fazendo recair sobre si mesma a atenção da plateia, a copla ou o ensemble funcionava muitas vezes como o verdadeiro motor da comédia oitocentista. Coplas epigramáticas, engraçadas, satíricas - eram estas características que despertavam o ouvido do público, quando ia assistir a um espetáculo de comédia. Com uma fronteira claramente definida entre o simples diálogo, decorrido no plano da ação, e as inserções musicais, desenvolvidas num plano exterior à realidade concreta, as coplas constituiam um território livre, autónomo e com regras próprias para o exercício irónico e a criação de trocadilhos e duplos sentidos. Não é raro encontrar enredos esquemáticos e diálogos elementares contrabalançados com coplas espevitantes de humor, subvertendo a hierarquia funcional dos dois planos textuais. 0 texto declamado passa a "pretexto", uma trama produzida exclusivamente para sustentar as coplas enquanto verdadeira substância do espetáculo.

Ainda na alçada do dramaturgo ficava muitas vezes a opção de solicitar a "música como meio expressivo" para enquadrar numa moldura emocional específica determinados momentos da ação:

\begin{tabular}{ll}
\hline Peça & Didascálias / deixas \\
\hline $\begin{array}{l}\text { A pedra das carapuças, } \\
\text { drama de costumes, original de Costa Cascais; }\end{array}$ & $\begin{array}{l}\text { Aurora, absorvida em seus pensamentos, dá alguns passos, pára e } \\
\text { mermanece em misero estado de abandono até o côro ir distante. Corre } \\
\text { músca de Joaquim Casimiro Júnior }\end{array}$ \\
(Teatro D. Maria II, 1858) & "Ai! que estou perdida! (Cae de joelhos). Virgem Nossa Senhora! Valei me!" \\
& (Fica n'esta posição, com o rosto obliquamente voltado para o fundo. Ouve- \\
Ato / cena & se uma harmonia suave por alguns instantes, a lua rompe por entre o \\
$3 . \%$ última & arvoredo, e alumia o rosto de Aurora. Vê-se no alto da scena, descendo a \\
& montanha, o Padre José, que desapparece por momentos, entrando logo em \\
& scena pela E., e reconhecendo Aurora: - "Filha! Minha filha!" (Soccorre-a). \\
& Cae o panno.
\end{tabular}

Miguel o torneiro

imitação de José Romano; música de Joaquim Casimiro Júnior (T. Ginásio, 1853)
MIGUEL : Com mil diabos! Já me falta a paciência... arreda!... (empurra-a violentamente. Musica na orchestra) MARIA (dando um grito, e amparando-se a um movel para não cair): Ai!!
Categoria

Música como meio expressivo: "harmonia suave"

Música como meio expressivo: "música na orquestra"

Ato / cena

XVIII

\section{A lotaria do diabo}

Ato / cena

$1.0^{\circ} / 1$
A orchestra executa uma suave melodia. Abre-se o pano do fundo. Vê-se n'uma especie de paraizo uma houri. A melodia continua até que termine a falla seguinte.)

UMA HOURI. " De principes nasceste. - Os desvarios das mulheres, que occuparam o throno dos teus avós - accarretaram as iras de Allah sobre os teus reinos. Encantados hoje - só poderão ser descobertos por ti no dia em que encontrares uma mulher perfeita. [...] - arma-te e parte! Principe das esmeraldas, serás venturoso ainda!" (O pano de fundo fecha; cessa a melodia).

AZAIM (que tem caido de joelhos durante a falla da houri). Abençoada seja a tua prophecia, ó formosíssima houri!
Música como meio expressivo: "A orquestra executa uma suave melodia. [...] até que termine a fala"

* Não foi detetado o original francês desta peça, e a ausência da folha de rosto no único exemplar traduzido acessivel na Biblioteca Nacional de Portugal não permite averigua se a peça foi publicada como uma comédia, uma comédia-drama ou uma comédia ornada de couplets. 


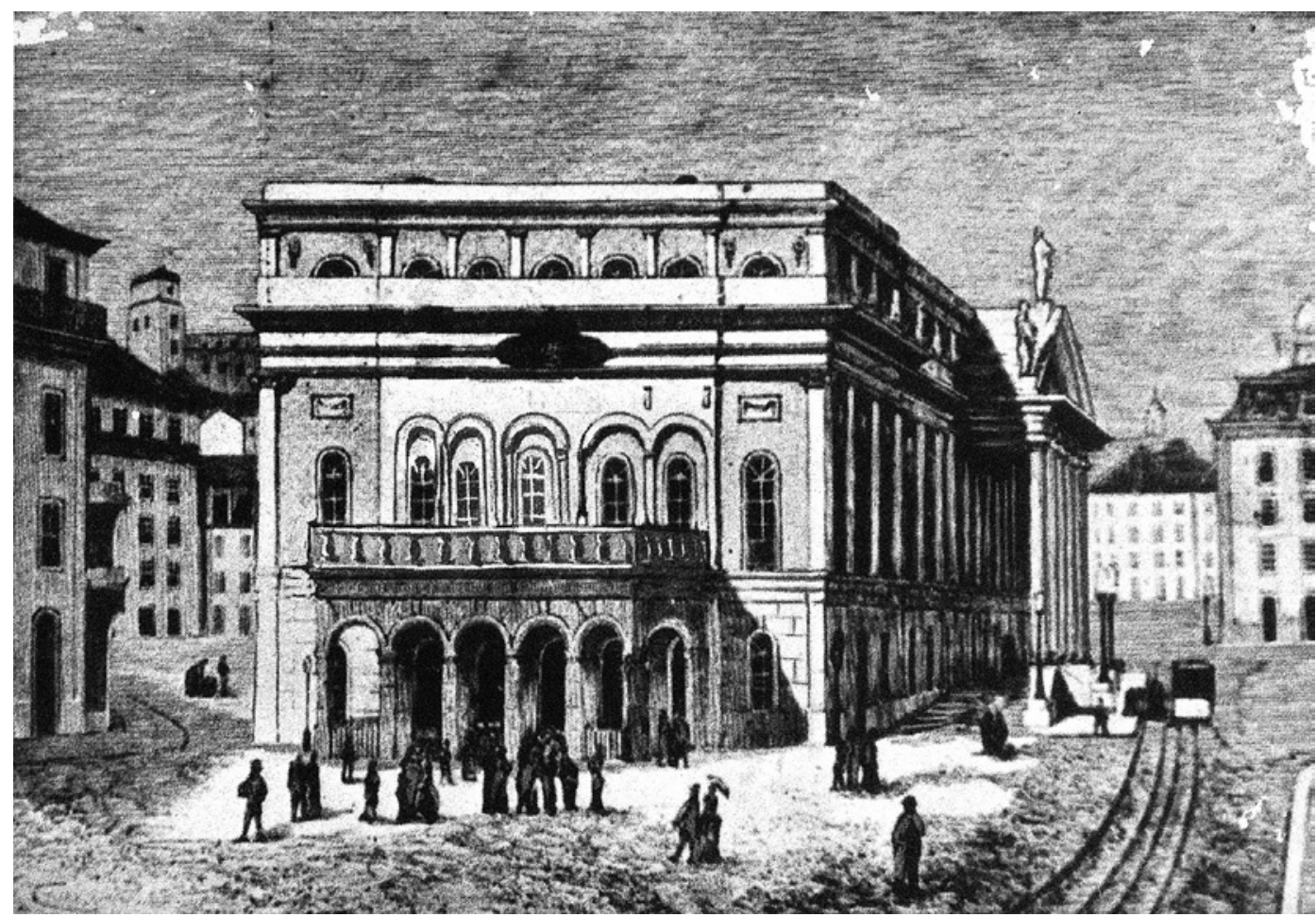

Teatro Nacional D. Maria II (Lisboa), vista da entrada lateral, s.d., programa da peça A sobrinha do marquês, de Almeida Garrett, TNDM II, [Arquivo Osório Mateus, Biblioteca da FLUL

Este tipo de números musicais - conhecidos genericamente por "mélodrames" e designados frequentemente de "harmonias" nos textos e nas partituras de cena portuguesas - aplicavam-se praticamente em todos os géneros teatrais. Não tinham uma justificação dramática; não constituiam separadores entre cenas; não eram um fim em si mesmos: estavam integralmente ao serviço da eficácia emocional, do impulsionamento do pathos. A estas três categorias musicais, postas em marcha logo na conceção dos textos teatrais, acrescentava-se uma outra na transposição para o palco: a "música como estruturação da ação". De forma a preparar o público para a representação, no início da peça e de cada um dos seus atos, a orquestra tocava sempre uma sinfonia ou um entreato. Durante a representação também podiam ocorrer curtas intervenções orquestrais, por vezes indicadas nos textos, para acompanhar mudanças de cena, entradas e saidas de atores, trocas de quadros ou assinalar o fecho de um ato:

\begin{tabular}{lll}
\hline Peça & Didascálias / deixas & Categoria \\
\hline Egas Moniz, & (Saem todos. A orchestra acompanha brandamente d'uma toada & Música como \\
drama, original de José da Silva Mendes Leal & melancholica, no estylo dos antigos romances nacionaes, esta sahida e a & estruturação da ação: \\
Júnior; música de Joaquim Casimiro Júnior & breve scena muda que se segue.) & mudança de cena
\end{tabular}

(Teatro D. Maria II, 1862)

Ato / cena

$1 . \% 11$

\section{Fígados de Tigre,}

paródia de melodramas, original de Gomes de

Amorim; música compilada de vários autores

(Teatro D. Maria Il, 1857)

Ato / cena

$4 . \% \mathrm{~V}-\mathrm{VI} / \mathrm{XX}-\mathrm{XXI}$

\section{A lotaria do diabo}

Ato / cena

$1 . \% / \mathrm{V}-\mathrm{V} / \mathrm{VI}$
(O pano cai e torna a subir logo que se faz a mutação; a orquestra toca durante ela)
Música como

estruturação da ação: mudança de quadro 
Todas estas categorias musicais operavam

propositadamente como elementos ativos na gestão das tensões, na promoção de mudanças do próprio enredo e na dinamização global do espetáculo teatral. Um olhar mais atento e pormenorizado aos textos dramáticos - que não cabe no teor breve deste artigo - permite trazer à superficie mecanismos mais complexos de cruzamento e sobreposição de categorias, para responder à eficácia dramática sem sacrificio de uma conceção verosímil do drama. Números de música com justificação dramática como se pode ver no exemplo seguinte, com a música surgindo de um mosteiro nas proximidades, e executada por trás do palco - impregnavam a cena e o monólogo ou o diálogo decorrentes de uma tonalidade emocional, mascarando a categoria funcional de "música como meio expressivo" numa legitimada categoria de "música como representação de música":

\begin{tabular}{lll}
\hline Peça & Didascálias / deixas & Categoria \\
\hline $\begin{array}{l}\text { Oastrólogo, drama, original de Andrade Corvo; } \\
\text { música de Joaquim Casimiro Júnior }\end{array}$ & D. VIOLANTE & Música como \\
(Teatro D. Maria II, 1853) & N'outro tempo, n'outro logar; longe deste tenebroso mundo, muito longe & representação de \\
& destas paixões da terra, havemos de ser felizes. - Eu vi, Mendo, esta noute & música: música \\
Ato / cena & antevi a nossa felicidade futura. - Era um paraiso. (Ouve-se uma musica & religiosa vinda do \\
$5 . / \mathrm{N}$ & de órgão e um coro, muito ao longe até ao fim da scena.) Um campo de & mosteiro / Música \\
& flores maravilhosas, com um perfume inebriante, um lago coberto de & como meio expressivo: \\
& diamantes, de uma serenidade e formosura sem igual no mundo; [...] & "Era um paraiso. (Ouve- \\
& & se uma musica [...] até \\
& & ao fim da scena.)"
\end{tabular}

\section{Contextos do desempenho musical}

Tais jogos de manipulação levam-nos a um outro aspeto essencial da música teatral: a localização do seu desempenho no decurso da ação. A colocação da fonte sonora "dentro de cena" ou "fora de cena" alterava radicalmente a leitura que o acontecimento dramático, no seu todo, promovia no público.

No excerto anterior, por exemplo, a música surgia "por trás da cena", "muito ao longe". Era uma estratégia cénica recorrente e de particular efeito na fabricação da ilusão. A ação estendia-se para além dos limites do palco, a vida continuava para lá do cenário e as reminiscências chegavam a uma plateia transformada praticamente numa entidade intrusa, um coletivo que ouvia, ilicitamente, os sons de um acontecimento paralelo.

A generalidade da música teatral instrumental, no entanto, era desempenhada "fora de cena". Todas as inserções musicais concebidas com a função de "estruturação da ação" - sinfonia, entreatos e mudanças de cena - provinham, assim, da orquestra colocada no fosso ou entre a plateia e o palco, bem como a maior parte das inserções de "música como meio expressivo".

Monólogos, diálogos, ou mesmo fragmentos de ação sem texto, podiam ser acompanhados de pequenas intervenções instrumentais que subiam da orquestra e envolviam 0 palco e a plateia num subtil pano de fundo sonoro. A ocultação da fonte sonora suprimia qualquer sobreposição à ação, o público concentrava-se exclusivamente na contemplação da cena, e a música atuava subliminarmente na criação de uma atmosfera, ou na densificação da espessura emocional do momento dramático.

Contrariamente, em muitas inserções de "música como representação de música", a fonte sonora provinha, no todo ou em parte, de "dentro da cena". Um ou vários instrumentistas surgiam no palco incorporados na ação e desempenhavam o papel, tout court, de músicos em contexto de danças, festas, cerimónias ou rituais religiosos:

\begin{tabular}{lll}
\hline Peça & Didascálias / deixas & $\begin{array}{c}\text { Contexto de } \\
\text { desempenho }\end{array}$ \\
\hline A pedra das carapuças & Ouve-se a musica, que vem collocar-se no coreto. & Dentro de cena: \\
& Vozes - As cavalhadas! As cavalhadas! & instrumentistas no \\
Ato / cena & {$[\ldots .]$.} & palco \\
$4 . / X \mid$ & Começam as cavalhadas. & \\
& Saem oito cavalleiros, quatro de cada lado [...]. A musica vem na frente, \\
& tocando. Seguem os pagens, acompanhando a azemola; atraz, os oito \\
& cavalleiros, sahindo de cada lado, juntando-se no centro da scena, marchando \\
& atraz dos pagens, etc. A musica, na bocca da scena, divide-se e retira, metade \\
& pela direita e metade pela esquerda, indo, depois de reunida, collocar-se no \\
& coreto. [...] A musica continua tocando, e só pára quando todos saiam.
\end{tabular}


Ao integrar um grupo de músicos no palco, fazendo-o no entanto emergir por vezes de um conjunto mais alargado de instrumentos, o compositor teatral de serviço contribuía para a verosimilhança, como pretendia o dramaturgo, sem prescindir de emprestar grandiosidade musical à cena, numa lógica de puro espetáculo.

Por fim, há ainda peças em que um ou mais entreatos estabeleciam uma "ponte para a cena":

\begin{tabular}{lll}
\hline Peça & Didascálias / deixas & $\begin{array}{c}\text { Contexto de } \\
\text { desempenho }\end{array}$ \\
\hline O alcaide de Faro, drama, original de Costa & (Depois da introducção da orchestra, levanta-se o panno, e continúa a & Ponte para a cena: \\
Cascais; música de Santos Pinto & musica brandamente. Aben-Baran e varios cavalleiros e damas, todos de "Depois da \\
(Teatro D. Maria II, 1848) & joelhos, voltados para o angulo esquerdo do fundo, oram em silencio, com introducção da \\
& a maior devoção: passados alguns instantes, deitam a face no chão, pouco orchestra, levanta-se \\
Ato / cena & depois levantam-se. OAlcaide senta-se.) & opanno, e continúa a \\
$4 . \%$ musica & brandamente." \\
\hline
\end{tabular}

Sobretudo na conceção de dramas tendo em vista 0 exercício de um teatro ilusionista que, através de uma "quarta parede", pretendia separar as duas realidades - a do palco e a da plateia -, a música era por vezes chamada a fazer a ligação de uma zona à outra, prolongando-se para dentro da cena. É o caso do exemplo apresentado. $\mathrm{Na}$ transição do espaço da sala para o território fechado do drama, a música já em execução no entreato e surgindo do fosso transportava o espectador para a cena, criando um clima emocional propício à contemplação e a uma audição atenta.

\section{Recursos musicais}

A presença intensa da música no teatro declamado oitocentista tinha implicações no sistema produtivo e exigia a operacionalização de uma série de recursos.
Focando-nos apenas no universo lisboeta da década de quarenta a sessenta, cada um dos cinco espaços teatrais em funções tinha uma orquestra permanente, de entre doze a quinze instrumentistas nos teatros secundários (o da rua dos Condes, o Ginásio, o D. Fernando e o Salitre / Variedades) e vinte a vinte e sete no teatro nacional D. Maria II.

A execução das partes vocais ficava naturalmente a cargo dos próprios atores e, muito pontualmente, quando o número era executado "por trás da cena", de cantores. Para números corais de envergadura, recorria-se também a coralistas profissionais.

À exceção da sinfonia e dos entreatos, geralmente escolhidos pela direção da orquestra, todos os números musicais de cada peça estreada eram compostos de raiz por um compositor. Tendo em conta que a componente 
musical de um espetáculo teatral podia oscilar de um número musical (em comédias de um ato) a cinco ou dez números (em comédias e dramas de dois a cinco atos), quinze (em comédias ornadas de couplets) ou mesmo trinta números musicais (no caso das mágicas), não surpreende que vários compositores portugueses do século XIX tenham garantido o seu trabalho, subsistência e, nalguns casos até, verdadeira notoriedade através da colaboração persistente com os teatros de declamação de Lisboa.

Para as empresas teatrais, o dispêndio elevado com a composição e a execução musical, a que se somava frequentemente a da contratação de um corpo de baile para os números de dança, constituiam mais um custo obrigatório na manutenção de uma atividade artística complexa e muito competitiva, que tinha de responder às expetativas dos dramaturgos ou imitadores e sobretudo, do público.

\section{Conclusão}

Muito mais haveria a abordar no âmbito do teatro e da música teatral praticados em Portugal no século XIX. As estratégias compositivas mais recorrentes, as características formais e idiomáticas dos números de música, os referentes musicais exteriores trazidos para a cena, os processos de adaptação musical de repertório teatral importado, a repercussão da música de cena na rua e na esfera doméstica, as interações entre os atores e a plateia pela via musical - são múltiplas e densas as questões que ficam por referir. Da breve apresentação ao tema neste artigo, ficam porém assentes três factos do teatro de Oitocentos: na base da conceção e redação dramatúrgica está também uma lógica musical e performativa; a música desempenha ativamente funções específicas, inelutáveis e com contextos de desempenho próprios; a praxis teatral dá resposta e incorpora por inteiro no palco a dimensão musical do texto dramático. Ter em conta estes factos é fundamental para empreender uma aproximação que se pretenda justa e rigorosa ao repertório teatral oitocentista.

\section{Referências bibliográficas}

AMORIM, Francisco Gomes de (1984), Figados de Tigre, melodrama dos melodramas, Lisboa, Imprensa Nacional.

ARAÚJO, Luis António de (s.d.), o juiz eleito, scenas de costumes, origina em um acto, ornado de couplets, representada pela primeira vez no Theatro do Gymnasio Dramatico, em 26 de julho de 1854, [s. I.], [s. n.] BRAGA, Francisco J. da Costa (imit.) (1860), Um marquez feito à pressa, comedia em um acto, representada pella primeira vez no Theatro de Variedades na noite de 16 de Setembro de 1859. Lisboa, Livraria de J. Marques da Silva.

CARVALHAIS, Bento Leão da Cunha (1850), Dulce, Coimbra, Imprensa da Universidade.

CASCAIS, J. da Costa (1904), A pedra das carapuças, drama de costumes em 4 actos in Theatro, Lisboa, Empreza da História de Portugal, vol. 4.

-- (1904), 0 alcaide de Faro, drama original português em 5 actos, in Theatro, Lisboa, Empreza da História de Portugal, vol. 2.

CORVO, João de Andrade (1859), 0 astrologo, drama em 5 actos, Lisboa, Typografia Universal.

GARRET, Almeida (1984), As profecias do Bandarra in Teatro II, Lisboa, Círculo de Leitores.

LEAL Júnior, José da Silva Mendes (1863), Egas Moniz, drama em cinco actos, apresentado a concurso em 30 de junho de 1861, Rio de Janeiro, Typ. Economica.

OLIVEIRA, Joaquim Augusto de / PALHA, Francisco (1858), A loteria do diabo, comedia magica em tres actos e dezenove quadros, accommodada à scena portuguesa, representada pela primeira vez no Theatro de Variedades em a noite de 1 de fevereiro de 1858, Lisboa, Escriptorio do Theatro Moderno.

PALMEIRIM, Luis Augusto (1845), "...", in A Restauração, 10.01 